\title{
Enzyme-Free Electrochemical Glucose Sensors Prepared by Dealloying Pd-Ni-P Metallic Glasses
}

\author{
Yuqiao Zeng, ${ }^{1}$ Hua Xiang, ${ }^{1}$ Chunlei Yang, ${ }^{1}$ Shengchen Yang, \\ Luyang Chen, ${ }^{2}$ Mingwei Chen, ${ }^{2}$ Akihisa Inoue, ${ }^{2}$ Xuhai Zhang, ${ }^{1}$ and Jianqing Jiang ${ }^{1}$ \\ ${ }^{1}$ Jiangsu Key Laboratory of Advanced Metallic Materials, School of Materials Science and Engineering, \\ Southeast University, Nanjing 211189, China \\ ${ }^{2}$ Institute for Materials Research, Tohoku University, Sendai 980-8577, Japan \\ Correspondence should be addressed to Yuqiao Zeng; zyuqiao@hotmail.com
}

Received 21 February 2014; Revised 7 March 2014; Accepted 10 March 2014; Published 15 April 2014

Academic Editor: Na Chen

Copyright (C) 2014 Yuqiao Zeng et al. This is an open access article distributed under the Creative Commons Attribution License, which permits unrestricted use, distribution, and reproduction in any medium, provided the original work is properly cited.

\begin{abstract}
We report the formation of enzyme-free electrochemical glucose sensors by electrochemical dealloying palladium-containing Pd$\mathrm{Ni}-\mathrm{P}$ metallic glasses. When metallic glasses with different Pd contents are used as the dealloying precursor alloys, palladium-based nanoporous metals with different ligament and pore sizes can be obtained. The chemical compositions of the nanoporous metals also vary according to the different precursor compositions. All the as-obtained nanoporous metals exhibit electrochemical catalytic activity towards the oxidation of d-glucose, indicating that the nanoporous metals prepared by dealloying the Pd-Ni-P metallic glasses are promising materials for enzyme-free electrochemical glucose sensor.
\end{abstract}

\section{Introduction}

Dealloying (chemical or electrochemical) is a simple and effective way to prepare well-defined nanoporous metals (NPMs) that are regarded as one of the most promising new materials for functional applications in nanotechnology [1-5]. Since the nanoporosity is formed by a self-assembly process through surface diffusion instead of excavating one phase from a preseparated multiphase system, the dealloying precursors should be homogenous with no phase separation prior to dealloying [5]. Usually, crystalline intermetallic compounds or solid solution alloys are used as the dealloying precursors. Recently, there are some attempts to synthesize NPMs by dealloying metallic glasses. For example, using $\mathrm{Pd}_{30} \mathrm{Ni}_{50} \mathrm{P}_{20}$ metallic glass as a dealloying starting alloy, Yu et al. succeeded in fabricating pure NPPd which exhibited high catalytic activity towards the oxidation of formic acid [6], indicating that metallic glass is a new suitable system to form useful NPMs.

In this study, we report the formation of Pd-based NPMs which exhibit high catalytic activity towards the electrochemical oxidation of glucose. Enzyme-free electrochemical glucose sensors are based on the utilization of nonenzymatic catalyzer for the conversion of the target analytes into electrochemically detectable products. Due to the simple assembling and high sensitivity, the enzyme-free electrochemical glucose sensors have attracted considerable interest in the field of both industrial applications and theoretical applications. NPMs, such as NPAu and NPPt with a bicontinuous network structure and a tunable feature dimension, have proven to be very active in the oxidation of glucose, making them ideal glucose sensing material [7-9]. In this study, NPPd enzymefree electrochemical glucose sensors with high catalytic activity are successfully prepared by dealloying $\mathrm{Pd}_{x} \mathrm{Ni}_{80-x} \mathrm{P}_{20}$ metallic glasses.

\section{Experimental}

The $\mathrm{Pd}_{x} \mathrm{Ni}_{80-x} \mathrm{P}_{20}(x=10,20,40)$ mother alloys were prepared by melting the mixture of pure Pd (purity, $99.9 \mathrm{wt} \%$ ) and $\mathrm{Ni}$ (purity, $99.95 \mathrm{wt} \%$ ) elements with prealloyed Ni-P ingots in vacuum fused silica tubes, followed by $\mathrm{B}_{2} \mathrm{O}_{3}$ flux treatment. From the mother alloys, glassy ribbons with a thickness of about $0.02 \mathrm{~mm}$ and a width of about $2 \mathrm{~mm}$ were fabricated by single-roller melt-spinning technique at 


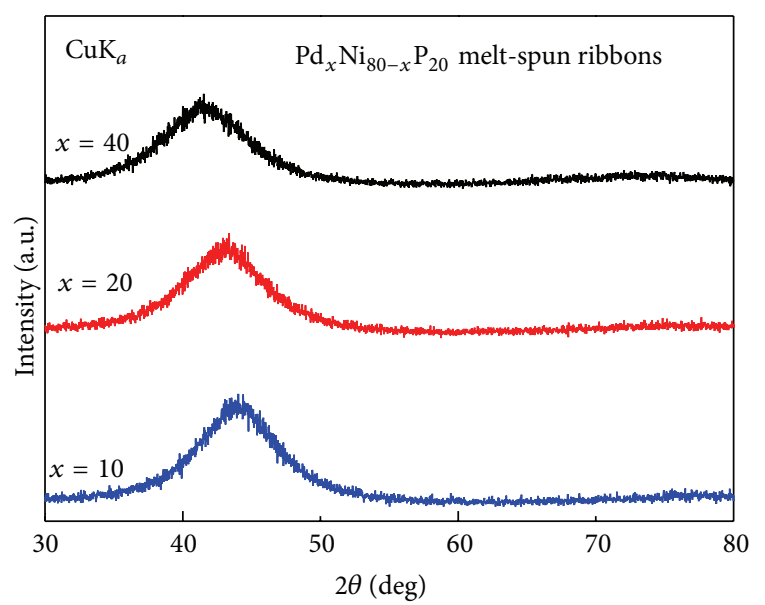

FIGURE 1: XRD patterns of the $\mathrm{Pd}_{x} \mathrm{Ni}_{80-x} \mathrm{P}_{20}(x=10,20,40)$ ribbon samples.

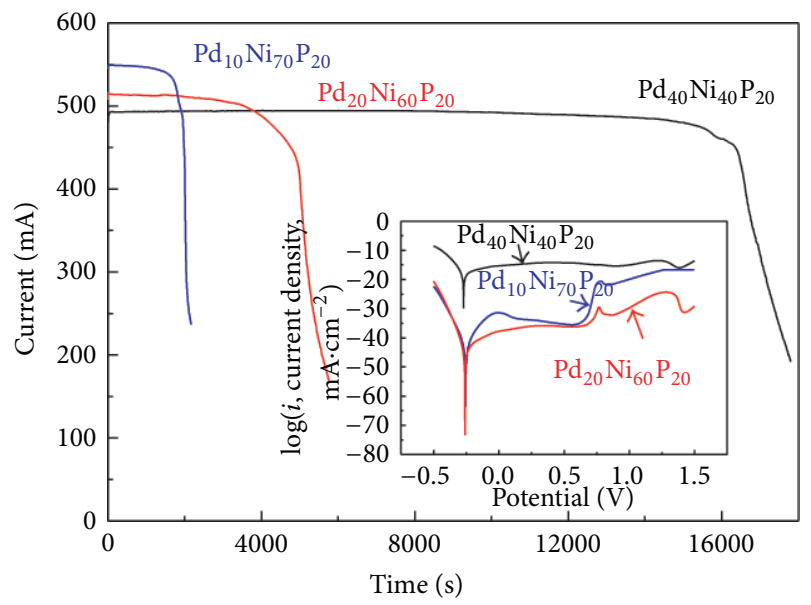

Figure 2: Chronoamperometric (current density versus time) curves for the potentiostatic dealloying of the $\mathrm{Pd}_{x} \mathrm{Ni}_{80-x} \mathrm{P}_{20}$ metallic glasses in $0.8 \mathrm{M} \mathrm{H}_{2} \mathrm{SO}_{4}+0.2 \mathrm{M} \mathrm{H}_{3} \mathrm{PO}_{4}$ solution at $0.80 \mathrm{~V}$ and the inset is the polarization curves of $\mathrm{Pd}_{x} \mathrm{Ni}_{80-x} \mathrm{P}_{20}$ metallic glasses in $0.8 \mathrm{M} \mathrm{H}_{2} \mathrm{SO}_{4}+0.2 \mathrm{M} \mathrm{H}_{3} \mathrm{PO}_{4}$.

a copper wheel velocity of about $40 \mathrm{~ms}^{-1}$. The amorphous structure of the as-prepared ribbons was confirmed by Xray diffraction (XRD). With the aim of clarifying the proper dealloying potential range, the potentiodynamic polarization test was performed on the $\mathrm{Pd}_{x} \mathrm{Ni}_{80-x} \mathrm{P}_{20}$ glassy ribbon in $0.8 \mathrm{M} \mathrm{H}_{2} \mathrm{SO}_{4}+0.2 \mathrm{M} \mathrm{H}_{3} \mathrm{PO}_{4}$ solution and $0.80 \mathrm{~V}$ (versus SCE) was chosen as the dealloying potential. The NPMs were then fabricated by potentiostatically $(0.80 \mathrm{~V}$ versus SCE) etching the $\mathrm{Pd}_{x} \mathrm{Ni}_{80-x} \mathrm{P}_{20}$ metallic glasses in a $0.8 \mathrm{M}$ $\mathrm{H}_{2} \mathrm{SO}_{4}+0.2 \mathrm{M} \mathrm{H}_{3} \mathrm{PO}_{4}$ mixed electrolyte. The dealloying process was carried out by using a classical three-electrode setup (ZF-10) with a saturated calomel reference electrode (SCE), a Pt counter electrode, and a $\mathrm{Pd}_{x} \mathrm{Ni}_{80-x} \mathrm{P}_{20}$ working electrode. The samples prepared by dealloying $\mathrm{Pd}_{10} \mathrm{Ni}_{70} \mathrm{P}_{20}$, $\mathrm{Pd}_{20} \mathrm{Ni}_{60} \mathrm{P}_{20}$ and $\mathrm{Pd}_{40} \mathrm{Ni}_{40} \mathrm{P}_{20}$ glasses are named as NPM 1\#, NPM 2\#, and NPM 3\#, respectively, in the following description. The morphology of the NPMs was observed by scanning electron microscopy (SEM) and the chemical compositions were identified by an energy dispersive X-ray spectrometer (EDS). The catalytic properties of the Pd-based NPMs towards the oxidation of $\mathrm{d}$-glucose were evaluated by cyclic voltammetry (CV) measurements in a CHI-760D electrochemical workstation, where the NPMs were used as the working electrode, a $\mathrm{Pt}$ foil was used as a counter electrode, and an SCE was used as the reference electrode. All the aqueous solutions used in the CV test were prepared with triply distilled water and deoxygenated by bubbling high purity $\mathrm{N}_{2}$ for half an hour.

\section{Results and Discussion}

The XRD patterns of the $\mathrm{Pd}_{x} \mathrm{Ni}_{80-x} \mathrm{P}_{20}(x=10,20$, and 40) ribbons in Figure 1 show only a broad diffraction maximum without any observable crystalline peaks, demonstrating the formation of a homogenous amorphous structure in all the dealloying precursors.

With the aim of finding out a proper dealloying potential for the three glasses with different Pd content, the potentiodynamic polarization test is performed on $\mathrm{Pd}_{x} \mathrm{Ni}_{80-x} \mathrm{P}_{20}$ ribbon in $0.8 \mathrm{M} \mathrm{H}_{2} \mathrm{SO}_{4}$ and $0.2 \mathrm{M} \mathrm{H}_{3} \mathrm{PO}_{4}$ solutions and the results are shown in the inset of Figure 2; all the $\mathrm{Pd}_{x} \mathrm{Ni}_{80-x} \mathrm{P}_{20}$ ribbons firstly experience a spontaneous passivation in the anodic region (about 0 to $0.70 \mathrm{~V}$ ), where dealloying can hardly occur due to the extremely low current density. A rapid current density rise appears at about $0.75-0.80 \mathrm{~V}$ and the current "apex nasi" (critical dealloying potential) increases with the $\mathrm{Pd}$ content in $\mathrm{Pd}_{x} \mathrm{Ni}_{80-x} \mathrm{P}_{20}$. This result may be attributed to the difference in potential required to dissolve $\mathrm{Ni}$ and $\mathrm{Pd}$ components in their pure form. According to the theoretical computation [5] and practical experiments [10], the bulk critical dealloying potential of the precursor alloys increases as the content of the component with higher standard electrode potential increases. In this study, the standard electrode potential of $\mathrm{Pd} / \mathrm{Pd}^{2+}$ is $0.34 \mathrm{~V}$, much higher than that of $\mathrm{Ni} / \mathrm{Ni}^{2+}(-0.25 \mathrm{~V})$. Therefore, the increase of Pd in metallic glasses leads to higher critical dealloying potential. Since the selective etching of $\mathrm{Ni}$ and $\mathrm{P}$ can take place above $0.80 \mathrm{~V}$ in all the $\mathrm{Pd}_{x} \mathrm{Ni}_{80-x} \mathrm{P}_{20}$ glasses, $0.80 \mathrm{~V}$ is chosen as the standard dealloying potential to form NPMs. As is shown in Figure 2, the dealloying process of three glasses is mainly composed of two current stages, similar to that of dealloying solid solutions and intermetallic metals: steady stage and decay stage [11]. The steady stage increases obviously with increasing Pd content in the metallic glasses, which may be attributed to the different overpotential used in dealloying the glasses. Since it has the highest critical dealloying potential among the three glasses, the $\mathrm{Pd}_{40} \mathrm{Ni}_{40} \mathrm{P}_{20}$ glass is dealloyed at the lowest overpotential (the different between the applied dealloying potential and the critical dealloying potential). Similarly, the $\mathrm{Pd}_{10} \mathrm{Ni}_{70} \mathrm{P}_{20}$ glass is dealloyed at the highest overpotential. As a consequence, the dealloying kinetic decreases with the increasing Pd content in $\mathrm{Pd}_{x} \mathrm{Ni}_{80-x} \mathrm{P}_{20}$ glasses though the applied dealloying potential is the same for all three dealloying precursors.

Figure 3 shows the SEM images of the as-obtained NPM 1\# (a), NPM 2\# (b), and NPM 3\# (c). All the samples exhibit 


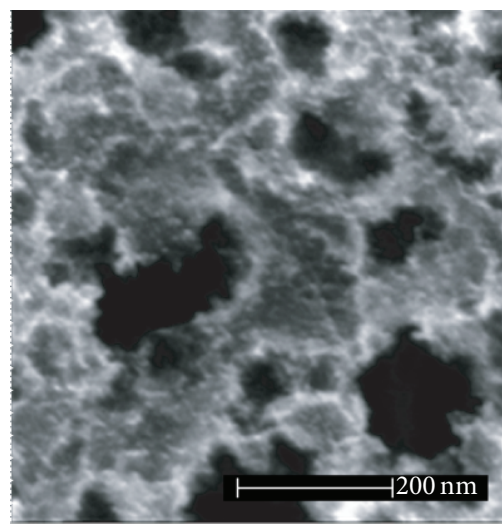

(a)

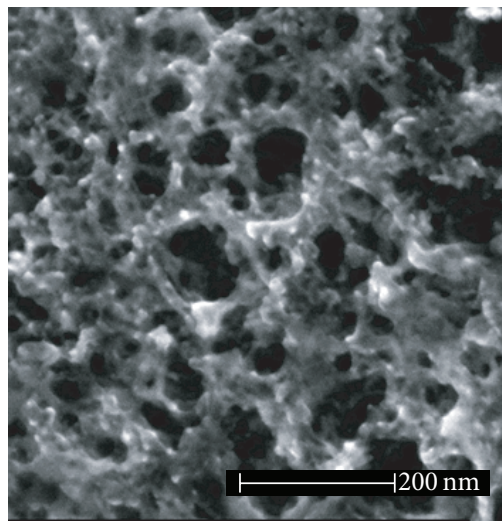

(d)

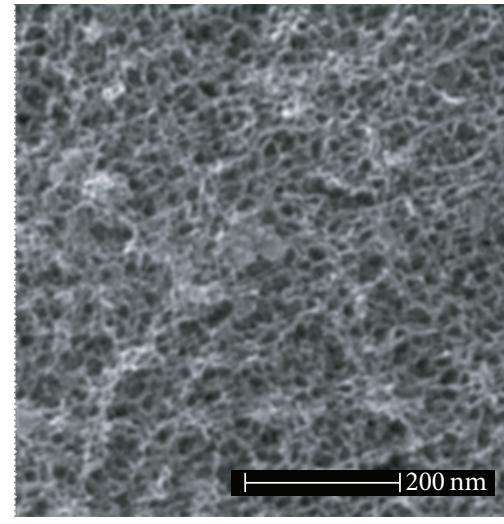

(b)

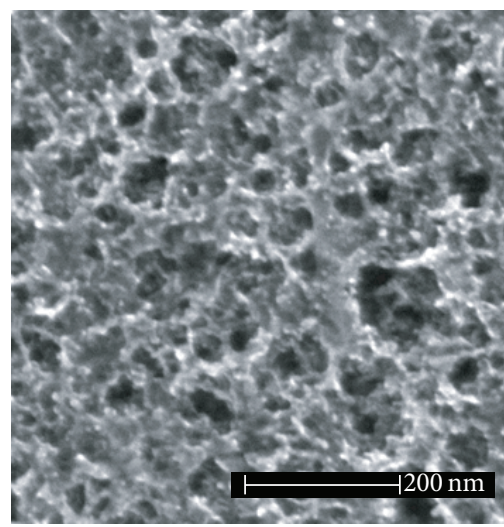

(e)

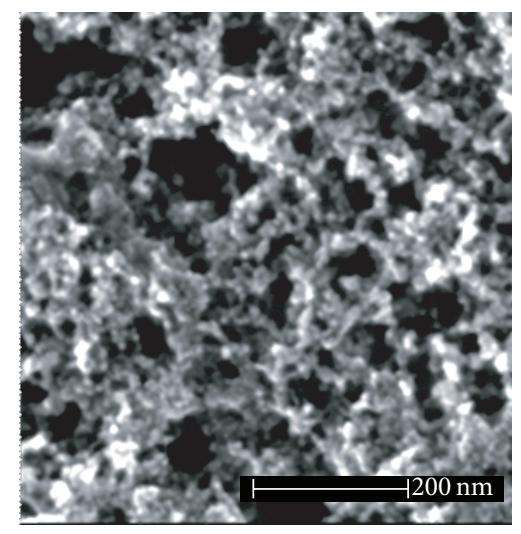

(c)

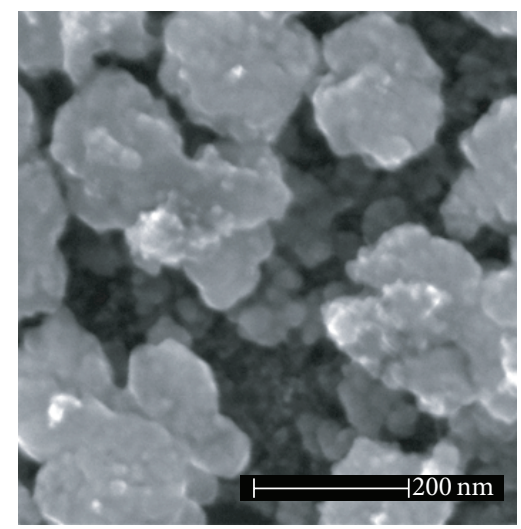

(f)

FIGURE 3: SEM images of the as-obtained NPMs (NPM 1\#: (a), NPM 2\#: (b), and NPM 3\#: (c)) and the NPMs subjected to 1000 potential cycles in $0.1 \mathrm{M} \mathrm{KOH}$ solution containing $50 \mathrm{mM}$ glucose (NPM 1\#: (d), NPM 2\#: (e), and NPM 3\#: (f)).

an open, three-dimensional, ligament-channel nanoporous structure, indicating that NPMs can be obtained by dealloying the $\mathrm{Pd}_{x} \mathrm{Ni}_{80-x} \mathrm{P}_{20}$ metallic glasses with a Pd content ranging within 10-40 at\%. NPM $1 \#$ contains a rather coarse nanoporous structure, as is evidenced by the inhomogeneous pores with a size ranging within 5-200 nm and ligaments with a width of $7-8 \mathrm{~nm}$. The increase of the Pd content to 20 at $\%$ in the metallic glass results in a refined nanostructure in NPM 2\#, where nanopores of $10-20 \mathrm{~nm}$ and metallic ligaments of $7-8 \mathrm{~nm}$ are homogenously dispersed. The finer structure may be attributed to the combination of relatively low dealloying overpotential and short dealloying time. Lower overpotential usually leads to higher activation energy for the diffusion of the noble element and thus improves the fine nanostructure in the NPM 2\# [5,12]. The short dealloying time is another important factor. Since the dealloying time is relatively short, the diffusion distance of $\mathrm{Pd}$ is limited. Thus, large pores and ligaments can barely form. Similar with NPM 1\#, NPM 3\# exhibits a coarse microstructure with nanopores ranging within $10-100 \mathrm{~nm}$ and metallic ligaments within $10-50 \mathrm{~nm}$. The coarsening of NPM $3 \#$ may be caused by the much longer dealloying time. The dealloying kinetic of $\mathrm{Pd}_{40} \mathrm{Ni}_{40} \mathrm{P}_{20}$ is the lowest among the glasses in this study and longer dealloying time is required to fully dealloy the $\mathrm{Pd}_{40} \mathrm{Ni}_{40} \mathrm{P}_{20}$ glass. In the located areas where the selective cession is complete, pure coarsening of the ligaments takes place and leads to located collapse. The morphology of NPM 3\#, thus, becomes coarse and inhomogeneous.

The chemical compositions of the NPMs measured by EDS are summarized in Table 1 . The results show that all the NPMs are mainly composed of Pd, together with a small amount of Ni and P, indicating that Pd-based NPMs are obtained. The preservation of much positive $\mathrm{Ni}$ and $\mathrm{P}$ elements in porous Pd can be explained by the core-shell structure which forms during dealloying [13]. When the positive elements ( $\mathrm{Ni}$ and $\mathrm{P}$ ) dissolve, the inert $\mathrm{Pd}$ atoms will be liberated and accumulated on the surface of the ligaments, forming a Pd or Pd-rich shell. If the applied dealloying potential is lower than the critical dealloying potential of the newly formed shell, no further dissolution is possible. Both $\mathrm{Ni}$ and $\mathrm{P}$ residuals in NPMs decrease with the increasing $\mathrm{Pd}$ content in $\mathrm{Pd}_{x} \mathrm{Ni}_{80-x} \mathrm{P}_{20}$ metallic glasses; that is, Ni decreases from 5.94 at\% in NPM $1 \#$ to 3.00 at\% in NPM $3 \#$, and P goes down from 4.1 at\% NPM 1 \# to 2.00 at $\%$ in NPM $3 \#$ when the Pd content in the glass precursors increases from 10 to 40 at $\%$.

The electrocatalytic activities of the as-prepared NPMs towards glucose electrooxidation were characterized by $\mathrm{CV}$ curves in $0.1 \mathrm{M} \mathrm{KOH}$ alkaline aqueous solutions with and without $50 \mathrm{mM}$ of glucose (Figure 4). In $0.1 \mathrm{M} \mathrm{KOH}+50 \mathrm{mM}$ glucose solutions, all the NPMs exhibit a sharp current 


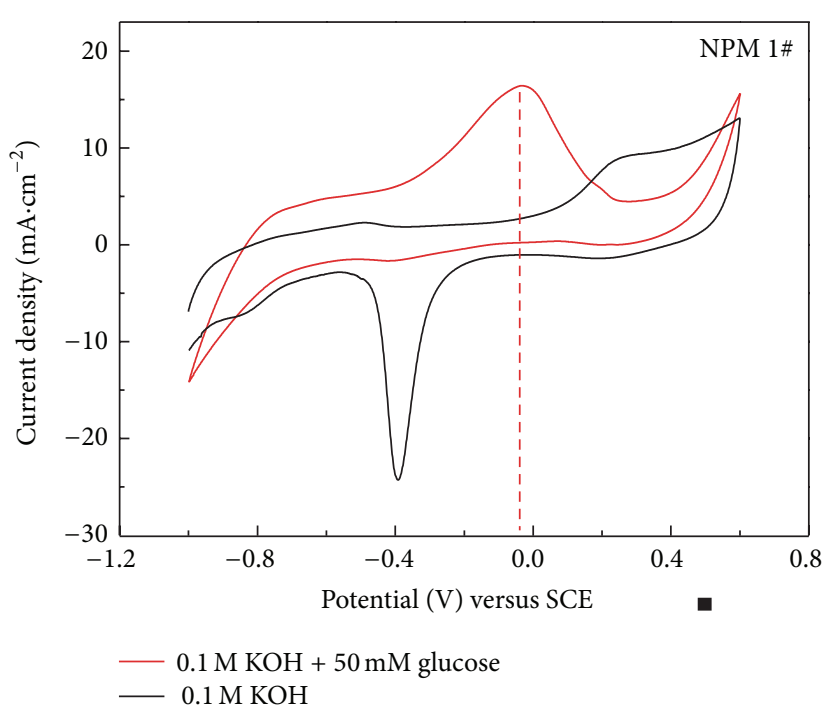

(a)

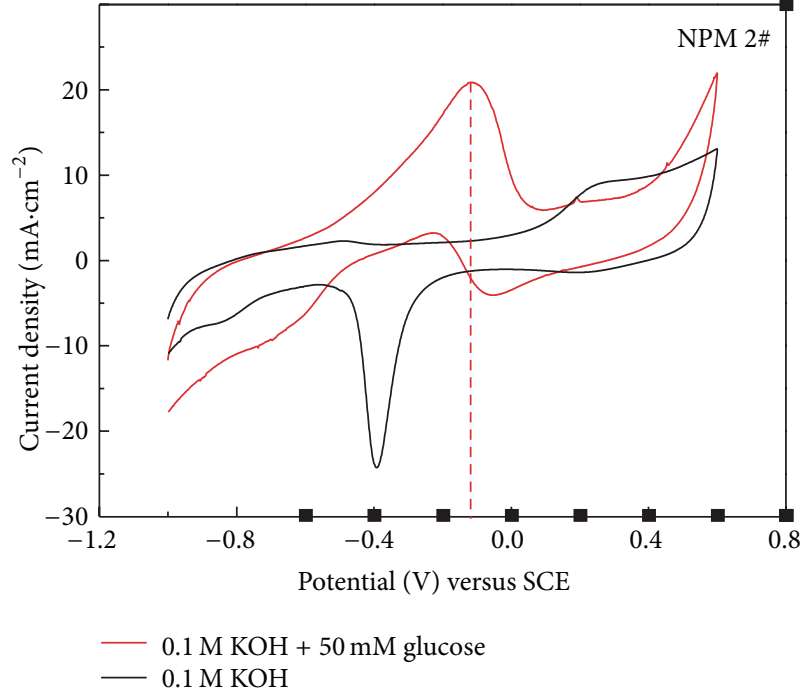

(b)

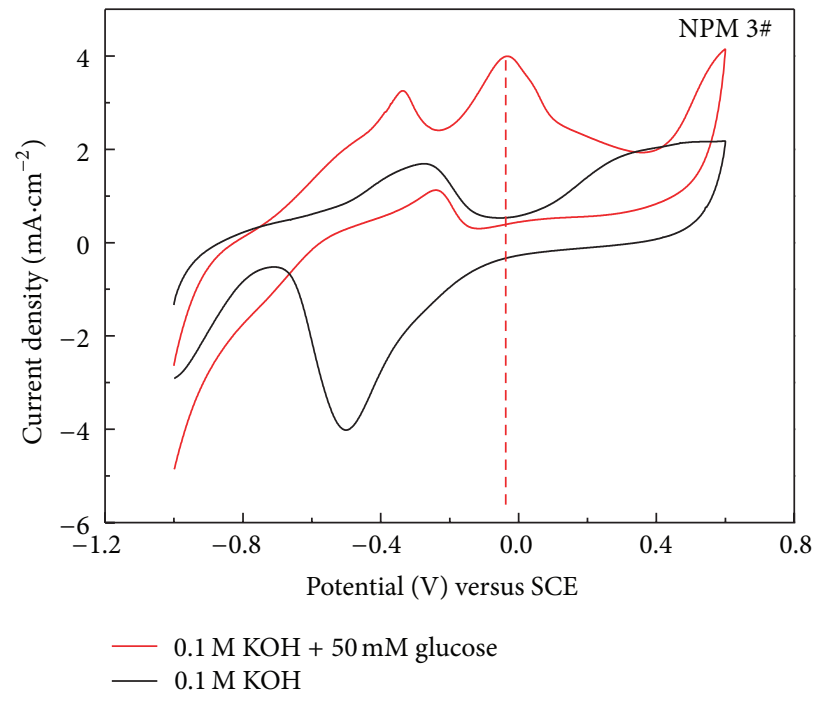

(c)

Figure 4: CV curves of the NPMs in $0.1 \mathrm{M} \mathrm{KOH}$ solution with and without $50 \mathrm{mM}$ glucose, scan rate: $0.05 \mathrm{~V} / \mathrm{s}$.

TABLE 1: Chemical compositions of the as-obtained NPMs.

\begin{tabular}{lccc}
\hline Samples & Pd (at\%) & $\mathrm{Ni}($ at $\%)$ & $\mathrm{P}($ at $\%)$ \\
\hline NPM 1\# & 89.54 & 5.94 & 4.1 \\
NPM 2\# & 90.74 & 3.55 & 5.71 \\
NPM 3\# & 95.00 & 3.00 & 2.00 \\
\hline
\end{tabular}

density peak at the potential range from $-0.10 \mathrm{~V}$ to $-0.03 \mathrm{~V}$, which cannot be detected in pure $\mathrm{KOH}$ solution. According to the former related reports, the current peak is associated to the absorption of $\mathrm{OH}^{-1}$ and the oxidation of glucose and intermediate [14], indicating that the NPMs prepared by dealloying the $\mathrm{Pd}_{x} \mathrm{Ni}_{80-x} \mathrm{P}_{20}$ metallic glasses have catalytic activity towards the electrochemical oxidation of glucose.
The current density/the potential of oxidation peak of NPM $1 \#$, NPM 2\# and NPM $3 \#$ are about $16.3 \mathrm{~mA} \cdot \mathrm{cm}^{-2} /-0.03 \mathrm{~V}$, $20.9 \mathrm{~mA} \cdot \mathrm{cm}^{-2} /-0.1 \mathrm{~V}$ and $4 \mathrm{~mA} \cdot \mathrm{cm}^{-2} /-0.03 \mathrm{~V}$, respectively. Clearly, NPM 2\# with the smallest pore size shows the highest oxidation current density and the lowest oxidation potential. Similar phenomenon has been found in other NPMs. For instance, Ge et al. studied the size effect of NPAu for methanol electrooxidation. They found that the smaller pore and ligament size leads to higher electrooxidation activity, consistent with our results [3].

The electrochemical stabilities of the NPMs prepared by dealloying $\mathrm{Pd}_{x} \mathrm{Ni}_{80-x} \mathrm{P}_{20}$ glasses are also investigated by $\mathrm{CV}$ tests for 1000 potential cycles performed in $\mathrm{KOH}$ alkaline aqueous solutions with $50 \mathrm{mM}$ glucose and the results are shown in Figure 5. After 1000 times of CV scans, the oxida- 


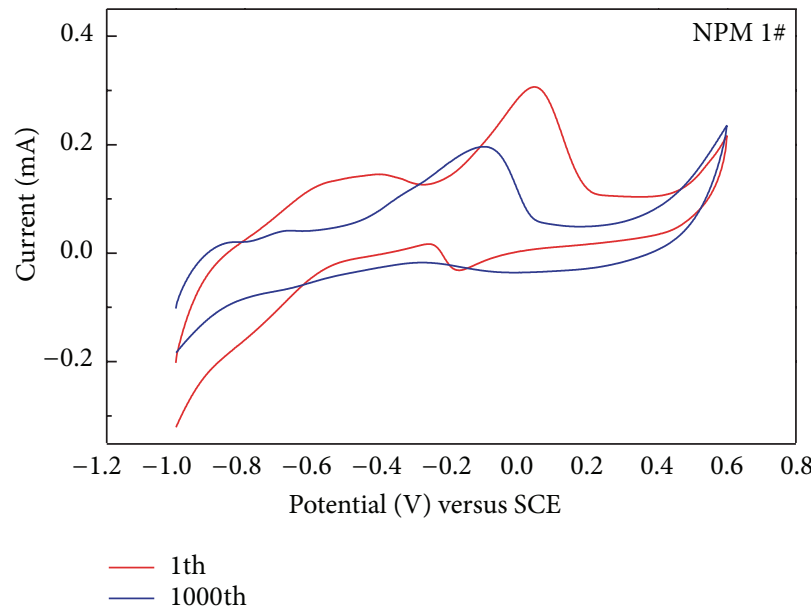

(a)

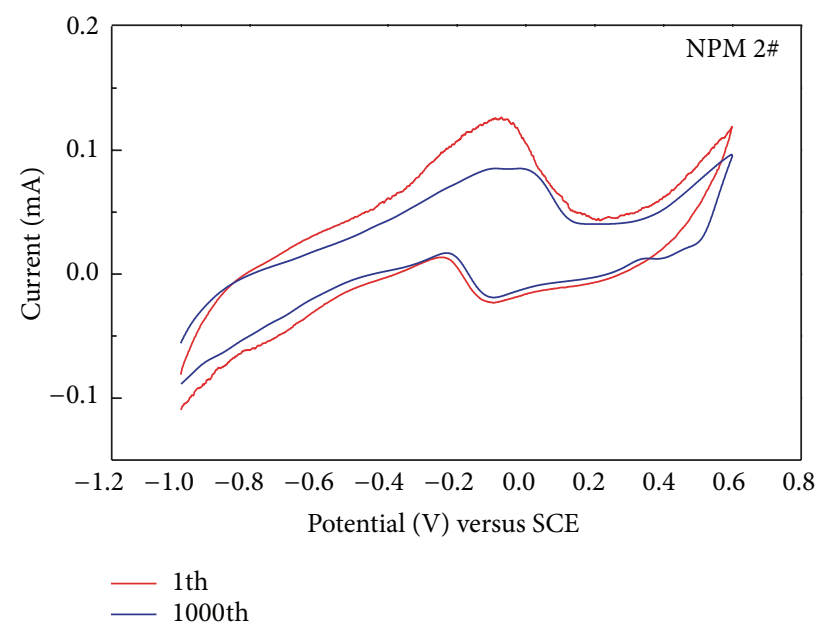

(b)

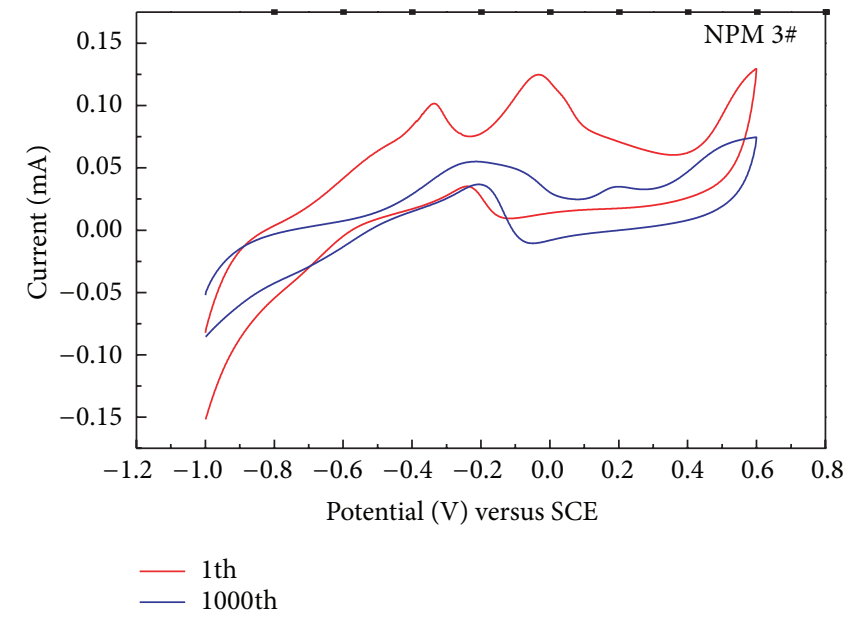

(c)

FIGURE 5: CV curves of the NPMs in $0.1 \mathrm{M} \mathrm{KOH}$ solutions containing $50 \mathrm{mM}$ glucose during 1000 potential cycles.

tion peak of NPM $1 \#$ shifts to lower potential and the peak density drops to $67 \%$ of the first test value. In the case of the NPM $2 \#$, the peak density is $64 \%$ of the first test value while the peak potential does not move. For NPM 3\#, the catalytic activity suffers the most serious gradation, as evidenced from the disappearance of the characteristic oxidation peak. To further clarify the reason which leads to the different catalytic stability of the NPMs, the morphology of the NPMs that undergo 1000 times of CV scans is investigated and the results are shown in Figures 3(d)-3(e). Coarsening of the nanopores and ligaments can be vividly seen in all the NPMs. In NPM 1\#, the pores size is almost the same as that of the as-obtained NPM 1\#, but the ligaments increase up to about $25-50 \mathrm{~nm}$. In NPM 2\#, the pores size increases up to $10-100 \mathrm{~nm}$ and the ligaments are about $25-50 \mathrm{~nm}$. The most apparent nanostructure coarsening can be observed in NPM 3\# after 1000 times of CV scans. The ligaments degenerate and aggregate to nanoparticles with a size of about $200 \mathrm{~nm}$ and the bicontinuous ligaments-nanoporous structure can hardly be seen. The coarsenes structure may cause the great decrease of the active Pd sites and the catalytic actively of the NPMs.

\section{Conclusion}

Pd-based NPMs can be prepared by dealloying the $\mathrm{Pd}_{x} \mathrm{Ni}_{80-x} \mathrm{P}_{20}$ metallic glasses $(x=10,20,40)$. When the content of $\mathrm{Pd}$ content is 20 at $\%$ in the $\mathrm{Pd}_{x} \mathrm{Ni}_{80-x} \mathrm{P}_{20}$ metallic glass, Pd-based NPM with the most homogeneous nanoporous structure can be obtained and it is chemically active to the electrochemical oxidation of glucose.

\section{Conflict of Interests}

The authors declare that there is no conflict of interests regarding the publication of this paper.

\section{Acknowledgments}

This work is supported by the National Science Foundation of China (51001026), the Project sponsored by SRF for ROCS, SEM (6812000013), the Project sponsored by Nanjing for ROCS (7912000011), Opening Project of Jiangsu Key Laboratory of Advanced Metallic Materials (AMM201101), and 
the Fundamental Research Funds for the Central Universities

(3212002205, 3212003102).

\section{References}

[1] J. Erlebacher, M. J. Aziz, A. Karma, N. Dimitrov, and K. Sieradzki, "Evolution of nanoporosity in dealloying," Nature, vol. 410, no. 6827, pp. 450-453, 2001.

[2] T. Fujita, L. H. Qian, K. Inoke, J. Erlebacher, and M. W. Chen, "Three-dimensional morphology of nanoporous gold," Applied Physics Letters, vol. 92, no. 25, Article ID 251902, 2008.

[3] X. Ge, R. Wang, P. Liu, and Y. Ding, "Platinum-decorated nanoporous gold leaf for methanol electrooxidation," Chemistry of Materials, vol. 19, no. 24, pp. 5827-5829, 2007.

[4] Z. Yi, X. Tan, G. Niu et al., "Facile preparation of dendritic Ag-Pd bimetallic nanostructures on the surface of $\mathrm{Cu}$ foil for application as a SERS-substrate," Applied Surface Science, vol. 258, no. 14, pp. 5429-5437, 2012.

[5] J. Erlebacher, "An atomistic description of dealloying porosity evolution, the critical potential, and rate-limiting behavior," Journal of the Electrochemical Society, vol. 151, no. 610, pp. 616624, 2004.

[6] J. Yu, Y. Ding, C. Xu, A. Inoue, T. Sakurai, and M. Chen, "Nanoporous metals by dealloying multicomponent metallic glasses," Chemistry of Materials, vol. 20, no. 14, pp. 4548-4550, 2008.

[7] D. van Noort and C. F. Mandenius, "Porous gold surfaces for biosensor applications," Biosensors and Bioelectronics, vol. 15, no. 3-4, pp. 203-209, 2000.

[8] Z. Liu, L. Huang, L. Zhang, H. Ma, and Y. Ding, "Electrocatalytic oxidation of d-glucose at nanoporous $\mathrm{Au}$ and $\mathrm{Au}-\mathrm{Ag}$ alloy electrodes in alkaline aqueous solutions," Electrochimica Acta, vol. 54, no. 28, pp. 7286-7293, 2009.

[9] Y. Ding, Y. J. Kim, and J. Erlebacher, "Nanoporous gold leaf: "Ancient technology"/advanced material," Advanced Materials, vol. 16, no. 21, pp. 1897-1900, 2004.

[10] J. Xu, Y. Wang, and Z. Zhang, "Potential and concentration dependent electrochemical dealloying of $\mathrm{Al}_{2} \mathrm{Au}$ in sodium chloride solutions," Journal of Physical Chemistry C, vol. 116, no. 9, pp. 5689-5699, 2012.

[11] N. Tavakkoli and S. Nasrollahi, "Non-enzymatic glucose sensor based on palladium coated nanoporous gold film electrode," Australian Journal of Chemistry, vol. 66, pp. 1097-1104, 2013.

[12] L. H. Qian and M. W. Chen, "Ultrafine nanoporous gold by lowtemperature dealloying and kinetics of nanopore formation," Applied Physics Letters, vol. 91, no. 8, Article ID 083105, 2007.

[13] A. J. Forty, "Corrosion micromorphology of noble metal alloys and depletion gilding," Nature, vol. 282, no. 5739, pp. 597-598, 1979.

[14] Y. Kuang, B. Wu, D. Hu, X. Zhang, and J. Chen, "Onepot synthesis of highly dispersed palladium nanoparticles on acetylenic ionic liquid polymer functionalized carbon nanotubes for electrocatalytic oxidation of glucose," Journal of Solid State Electrochemistry, vol. 16, no. 2, pp. 759-766, 2012. 

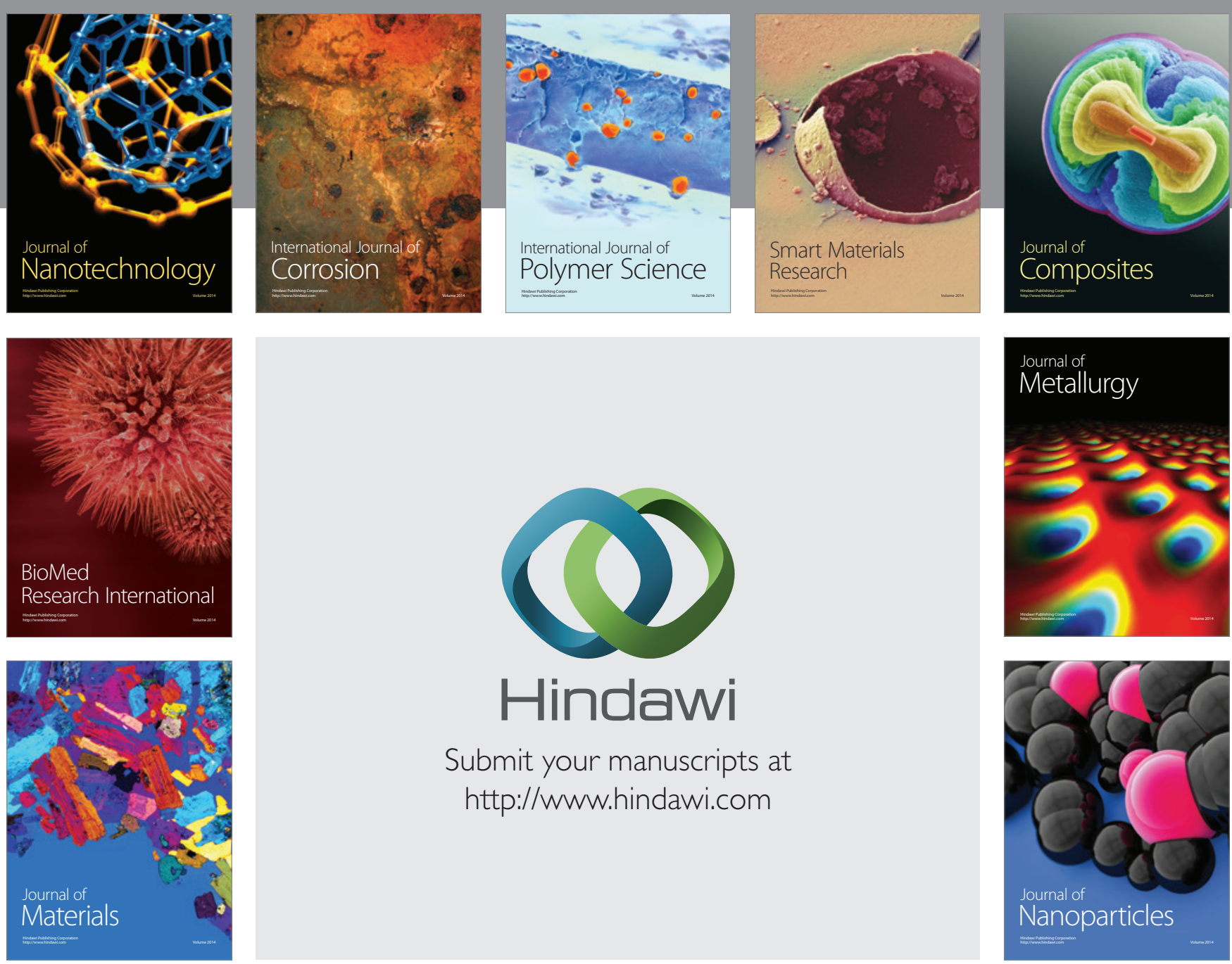

Submit your manuscripts at http://www.hindawi.com
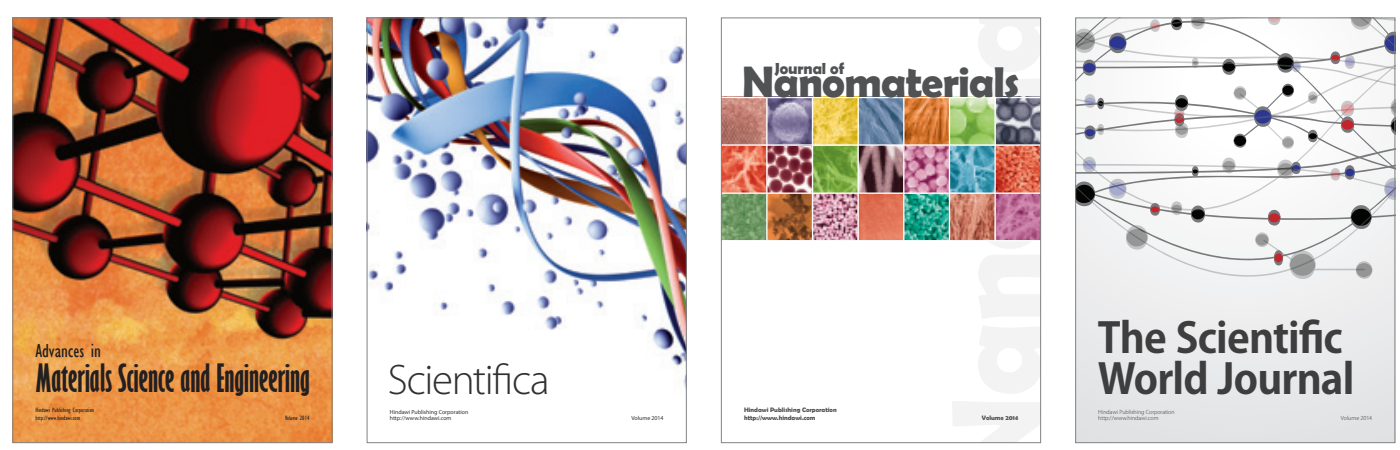

\section{The Scientific World Journal}
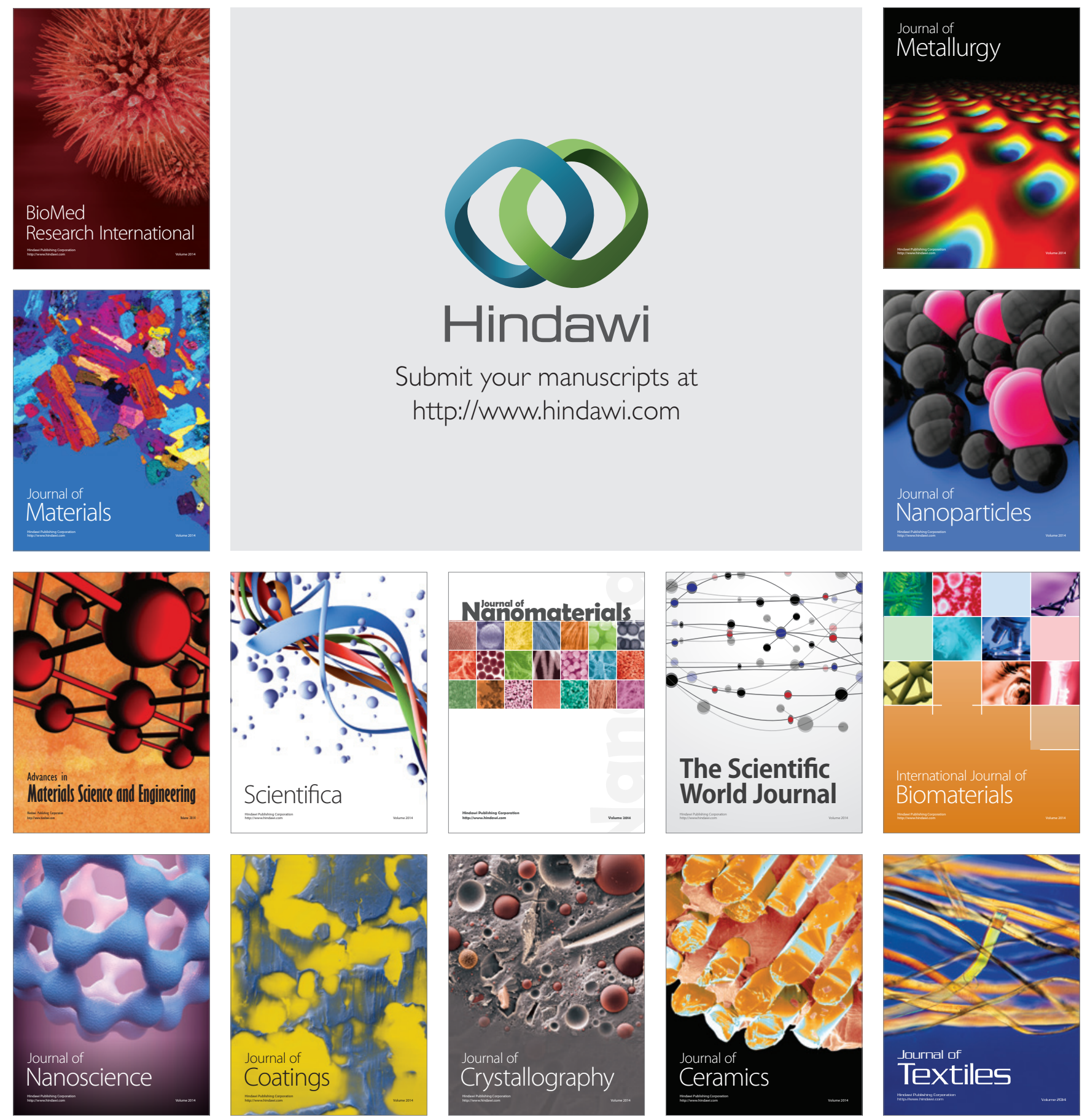